\title{
A SERIES-TYPE MULTISTAGE PRODUCTION SYSTEM WITH RANDOM DEMAND
}

\author{
YING-CHIEH CHEN
}

Received 12 December 2001

\begin{abstract}
We propose a mathematical model which considers the series-type product structure with $n-1$ predecessors. Our objective is to obtain the optimal production functions, in the planning horizon $[0, T]$, based on the assumptions (1) that the cost of production unit is a linear function of production quantity in a time unit, (2) that sales of finished goods occur at the end of planning horizon, and (3) that product demand is a random variable. Then the phenomenon of optimal solution is discussed.
\end{abstract}

2000 Mathematics Subject Classification: 49N90, 90B05, 90B30.

1. Introduction. Billington et al. [1] have described that there are four types of product structures in the multistage production systems: (1) series; (2) parallel; (3) assembly; (4) general. The simplest is the series-type product structure which illustrates a single product, produced in a series of steps. Zangwill [7] and Love [6] use a concave cost structure and present relatively efficient solution techniques. Whatever type of the multistage production systems, the assumption of the demand schedule for the end products has been established, and then one determines the lot sizes in each stage to minimize the total costs. On the contrary, the probabilistic demand is discussed in the inventory system. The typical one is the classical newsboy problem. It is a single-period, singleproduct inventory problem which considers the inventory size to be ordered for the sake of meeting random demand so as to maximize expected profit while balancing holding and shortage costs. There are many papers to discuss this problem in recent years. For example, Eppen [4] presented a multilocation newsboy problem with normal distribution of a location's demand, identical linear holding, and penalty cost functions. Chen and Lin [3] extend Eppen's model by considering the concave cost function with unspecified distribution of demand, then show that the Eppen's results are still true.

M. S. Chen and Y. C. Chen [2] have constructed a mathematical model for the newsboy problem with production and holding costs. The problem is, in the planning horizon $[0, T]$, how should the decision makers control the production rates to meet the random demand at the end of the period such that the expected profit is optimal? However, they assumed that the product structure is single-stage. Thus, we extend it by assuming that the product structure 
is series-type with $n-1$ predecessors. Then how should the decision makers control the production rates at each stage to meet the random demand at the end of planning period such that the expected profit is optimal?

2. Notation and assumptions. For the sake of convenience, the following notation and assumptions are used in this paper:

(i) $[0, T]$ : the available time interval for production and $T$ is the selling time;

(ii) $v$ : the price unit of produced goods;

(iii) $h_{i}$ : the holding unit cost of $i$ th semifinished goods in a time unit, $i=$ $1, \ldots, n-1$, let $h_{0}=0$, and $h_{n}$ is the holding unit cost of finished goods in a time unit;

(iv) $b$ : the loss or treatment cost per unit of surplus goods. It occurs when the quantity of inventory on hand at time $T$ is larger than the quantity of goods in demand;

(v) $p$ : the penalty cost per unit of lacking goods. It occurs when the quantity of inventory on hand is less than the quantity of goods in demand;

(vi) $S$ : the quantity of goods in demand at time $T$. Here, $S$ is a random variable, its probability density function is $f(s)$, and its cumulative distribution function is

$$
F(s)=\int_{0}^{s} f(t) d t
$$

(vii) $\left[t_{i}, T\right]$ : the time interval during which the decision maker is actually engaged in the production of $i$ th semifinished goods, and $t_{i}$ is the time to begin production of $i$ th semifinished goods, where $t_{i} \geq 0$ and $i=1, \ldots, n-1$. Let $\left[t_{n}, T\right]$ be the time interval during which the decision maker is actually engaged in the production of finished goods and let $t_{n}$ be the time to begin the production of finished goods, where $t_{n} \geq 0$;

(viii) $x_{i}(t)$ : the cumulative production of $i$ th semifinished goods at time $t$, that is, the total production of semifinished goods in the time interval $\left[t_{i}, t\right]$, where $x_{i}\left(t_{i}\right)=0$ and $i=1, \ldots, n-1$. Furthermore, $x_{n}(t)$ is the total production of finished goods in the time interval $\left[t_{n}, t\right]$, where $x_{n}\left(t_{n}\right)=0$ and $x_{n}(T)$ is the total inventory on hand at time $T$. When the decision makers make extra production plans in addition to the routine work, the cost will burden them because of the capital and the human resources. So, the production unit cost will increase as the production increases. Hence, in this paper, we assume that the production unit cost is an increasing function of production in the time unit. If the decision makers do not have production, they do not have to pay for the cost. Therefore, we have

(ix) $c_{i} x_{i}^{\prime}(t)$ : the production unit cost of the $i$ th semifinished goods at time $t$, where $c_{i}$ is a constant and $i=1,2, \ldots, n-1$. Furthermore, $c_{n} x_{n}^{\prime}(t)$ is the production unit cost of finished goods at time $t$, where $c_{n}$ is a constant. 
3. Model. Using the notation of the previous section, we have that

(i) total production and holding costs of finished goods equals $\int_{t_{n}}^{T}\left[c_{n} x_{n}^{\prime 2}(t)\right.$ $\left.+h_{n} x_{n}(t)\right] d t$

(ii) total production and holding costs of the $i$ th semifinished goods in the time interval $\left[t_{i}, t_{i+1}\right]$ equals $\int_{t_{i}}^{t_{i+1}}\left[c_{i} x_{i}^{\prime 2}(t)+h_{i} x_{i}(t)\right] d t$ for all $i=1,2, \ldots$, $n-1$;

(iii) total production and holding costs of the $i$ th semifinished goods in the time interval $\left[t_{i+1}, T\right]$ equals $\int_{t_{i+1}}^{T}\left[c_{i} x_{i}^{\prime 2}(t)+h_{i}\left(x_{i}(t)-x_{i+1}(t)\right)\right] d t$ for all $i=1,2, \ldots, n-1$;

(iv) total production and holding costs of the $i$ th semifinished goods in the time interval $\left[t_{i}, T\right]$ equals $\int_{t_{i}}^{T}\left[c_{i} x_{i}^{\prime 2}(t)+h_{i} x_{i}(t)\right] d t-\int_{t_{i+1}}^{T} h_{i} x_{i+1}(t) d t$.

So, total production and holding costs of all semifinished goods equals

$$
\begin{aligned}
& \sum_{i=1}^{n-1} \int_{t_{i}}^{T}\left[c_{i} x_{i}^{\prime 2}(t)+h_{i} x_{i}(t)\right] d t-\sum_{i=1}^{n-1} \int_{t_{i+1}}^{T} h_{i} x_{i+1}(t) d t \\
& \quad=\sum_{i=1}^{n-1} \int_{t_{i}}^{T}\left[c_{i} x_{i}^{\prime 2}(t)+h_{i} x_{i}(t)\right] d t-\sum_{i=2}^{n} \int_{t_{i}}^{T} h_{i-1} x_{i}(t) d t \\
& =\sum_{i=1}^{n-1} \int_{t_{i}}^{T}\left[c_{i} x_{i}^{\prime 2}(t)+h_{i} x_{i}(t)\right] d t-\sum_{i=1}^{n} \int_{t_{i}}^{T} h_{i-1} x_{i}(t) d t \quad\left(h_{0}=0\right) \\
& =\sum_{i=1}^{n-1} \int_{t_{i}}^{T}\left[c_{i} x_{i}^{\prime 2}(t)+\left(h_{i}-h_{i-1}\right) x_{i}(t)\right] d t-\int_{t_{n}}^{T} h_{n-1} x_{n}(t) d t
\end{aligned}
$$

Thus, total production and holding costs equals

$$
\begin{gathered}
\int_{t_{n}}^{T}\left[c_{n} x_{n}^{\prime 2}(t)+h_{n} x_{n}(t)\right] d t-\int_{t_{n}}^{T} h_{n-1} x_{n}(t) d t \\
+\sum_{i=1}^{n-1} \int_{t_{i}}^{T}\left[c_{i} x_{i}^{\prime 2}(t)+\left(h_{i}-h_{i-1}\right) x_{i}(t)\right] d t \\
=\sum_{i=1}^{n} \int_{t_{i}}^{T}\left[c_{i} x_{i}^{\prime 2}(t)+\left(h_{i}-h_{i-1}\right) x_{i}(t)\right] d t .
\end{gathered}
$$

Since the for-sale quantity of goods $\min \left\{x_{n}(T), S\right\}$ is a random variable, we have that

(i) the expected revenue equals $\int_{0}^{x_{n}(T)} v s f(s) d s+\int_{x_{n}(T)}^{\infty} v x_{n}(T) f(s) d s$;

(ii) the expected cost of surplus goods equals $\int_{0}^{x_{n}(T)} b\left(x_{n}(T)-s\right) f(s) d s$;

(iii) the expected cost of shortage goods equals $\int_{x_{n}(T)}^{\infty} p\left(s-x_{n}(T)\right) f(s) d s$. 
If our objective is the profit optimization, then the mathematical model is as follows:

$$
\begin{aligned}
\operatorname{Max} & \int_{0}^{x_{n}(T)}\left[v s-b\left(x_{n}(T)-s\right)\right] f(s) d s \\
& +\int_{x_{n}(T)}^{\infty}\left[v x_{n}(T)-p\left(s-x_{n}(T)\right)\right] f(s) d s \\
& -\sum_{i=1}^{n} \int_{t_{i}}^{T}\left[c_{i} x_{i}^{\prime 2}(t)+\left(h_{i}-h_{i-1}\right) x_{i}(t)\right] d t
\end{aligned}
$$

subject to $x_{i}\left(t_{i}\right)=0$ for all $i, x_{i}(T)=x_{n}(T)$ for all $i=1, \ldots, n-1, x_{1}(t) \geq$ $x_{2}(t) \geq x_{3}(t) \geq \cdots \geq x_{n}(t)$ for all $t \in\left[t_{n}, T\right], h_{i}>h_{i-1}$ for all $i=1,2, \ldots, n$, $h_{0}=0, t_{n} \geq t_{n-1} \geq \cdots \geq t_{1} \geq 0, x_{i}^{\prime}(t) \geq 0$ for all $t \in\left[t_{i}, T\right]$, for all $i=1,2, \ldots, n$, where $x_{i}(T), t_{i}$ are free for all $i$.

Now, let $\left(x_{1}^{*}(t), x_{2}^{*}(t), \ldots, x_{n}^{*}(t)\right)$ be the optimal solution of (3.3) and consider two feasible solutions

$$
\begin{gathered}
\left(x_{1}^{*}(t), \ldots, x_{i-1}^{*}(t), x_{i+1}^{*}(t), x_{i+1}^{*}(t), x_{i+2}^{*}(t), \ldots, x_{n}^{*}(t)\right), \\
\left(x_{1}^{*}(t), \ldots, x_{i-1}^{*}(t), x_{i}^{*}(t), x_{i}^{*}(t), x_{i+2}^{*}(t), \ldots, x_{n}^{*}(t)\right) .
\end{gathered}
$$

Therefore, using the fact that the objective value of $\left(x_{1}^{*}(t), x_{2}^{*}(t), \ldots, x_{n}^{*}(t)\right)$ is greater than the objective of $\left(x_{1}^{*}(t), \ldots, x_{i-1}^{*}(t), x_{i+1}^{*}(t), x_{i+1}^{*}(t), x_{i+2}^{*}(t), \ldots\right.$, $\left.x_{n}^{*}(t)\right)$, we have

$$
\begin{aligned}
& \int_{0}^{x_{n}^{*}(T)}\left[v s-b\left(x_{n}^{*}(T)-s\right)\right] f(s) d s+\int_{x_{n}^{*}(T)}^{\infty}\left[v x_{n}^{*}(T)-p\left(s-x_{n}^{*}(T)\right)\right] f(s) d s \\
& \quad-\sum_{i=1}^{n} \int_{t_{i}^{*}}^{T}\left[c_{i} x_{i}^{*^{\prime} 2}(t)+\left(h_{i}-h_{i-1}\right) x_{i}^{*}(t)\right] d t \\
& \geq \int_{0}^{x_{n}^{*}(T)}\left[v s-b\left(x_{n}^{*}(T)-s\right)\right] f(s) d s \\
& \quad+\int_{x_{n}^{*}(T)}^{\infty}\left[v x_{n}^{*}(T)-p\left(s-x_{n}^{*}(T)\right)\right] f(s) d s \\
& \quad-\sum_{k=1}^{i-1} \int_{t_{k}^{*}}^{T}\left[c_{k} x_{k}^{*^{\prime} 2}(t)+\left(h_{k}-h_{k-1}\right) x_{k}^{*}(t)\right] d t \\
& \quad-\int_{t_{i+1}^{*}}^{T}\left[c_{i} x_{i+1}^{*^{\prime} 2}(t)+\left(h_{i}-h_{i-1}\right) x_{i+1}^{*}(t)\right] d t \\
& \quad \sum_{k=i+1}^{n} \int_{t_{k}^{*}}^{T}\left[c_{k} x_{k}^{*^{\prime} 2}(t)+\left(h_{k}-h_{k-1}\right) x_{k}^{*}(t)\right] d t,
\end{aligned}
$$

which implies

$$
\int_{t_{i}^{*}}^{T}\left(x_{i+1}^{*^{\prime} 2}(t)-x_{i}^{*^{\prime} 2}(t)\right) d t \geq \frac{h_{i}-h_{i-1}}{c_{i}} \int_{t_{i}^{*}}^{T}\left(x_{i}^{*}(t)-x_{i+1}^{*}(t)\right) d t .
$$


Similarly, the objective value of $\left(x_{1}^{*}(t), x_{2}^{*}(t), \ldots, x_{n}^{*}(t)\right)$ is greater than the objective of $\left(x_{1}^{*}(t), \ldots, x_{i-1}^{*}(t), x_{i}^{*}(t), x_{i}^{*}(t), x_{i+2}^{*}(t), \ldots, x_{n}^{*}(t)\right)$, then we have

$$
\begin{aligned}
& \int_{0}^{x_{n}^{*}(T)}\left[v s-b\left(x_{n}^{*}(T)-s\right)\right] f(s) d s+\int_{x_{n}^{*}(T)}^{\infty}\left[v x_{n}^{*}(T)-p\left(s-x_{n}^{*}(T)\right)\right] f(s) d s \\
& \quad-\sum_{i=1}^{n} \int_{t_{i}^{*}}^{T}\left[c_{i} x_{i}^{*^{\prime} 2}(t)+\left(h_{i}-h_{i-1}\right) x_{i}^{*}(t)\right] d t \\
& \geq \int_{0}^{x_{n}^{*}(T)}\left[v s-b\left(x_{n}^{*}(T)-s\right)\right] f(s) d s \\
& \quad+\int_{x_{n}^{*}(T)}^{\infty}\left[v x_{n}^{*}(T)-p\left(s-x_{n}^{*}(T)\right)\right] f(s) d s \\
& -\sum_{k=1}^{i} \int_{t_{k}^{*}}^{T}\left[c_{k} x_{k}^{*^{\prime} 2}(t)+\left(h_{k}-h_{k-1}\right) x_{k}^{*}(t)\right] d t \\
& \quad-\int_{t_{i}^{*}}^{T}\left[c_{i+1} x_{i}^{*^{\prime} 2}(t)+\left(h_{i+1}-h_{i}\right) x_{i}^{*}(t)\right] d t \\
& -\sum_{k=i+2}^{n} \int_{t_{k}^{*}}^{T}\left[c_{k} x_{k}^{*^{\prime} 2}(t)+\left(h_{k}-h_{k-1}\right) x_{k}^{*}(t)\right] d t
\end{aligned}
$$

which implies that

$$
\frac{h_{i+1}-h_{i}}{c_{i+1}} \int_{t_{i}^{*}}^{T}\left(x_{i}^{*}(t)-x_{i+1}^{*}(t)\right) d t \geq \int_{t_{i}^{*}}^{T}\left(x_{i+1}^{*^{\prime} 2}(t)-x_{i}^{*^{\prime} 2}(t)\right) d t .
$$

Combining (3.6) and (3.8), we have

$$
\begin{gathered}
\frac{h_{i}-h_{i-1}}{c_{i}} \int_{t_{i}^{*}}^{T}\left(x_{i}^{*}(t)-x_{i+1}^{*}(t)\right) d t \leq \frac{h_{i+1}-h_{i}}{c_{i+1}} \int_{t_{i}^{*}}^{T}\left(x_{i}^{*}(t)-x_{i+1}^{*}(t)\right) d t, \\
\left(\frac{h_{i}-h_{i-1}}{c_{i}}-\frac{h_{i+1}-h_{i}}{c_{i+1}}\right) \int_{t_{i}^{*}}^{T}\left(x_{i}^{*}(t)-x_{i+1}^{*}(t)\right) d t \leq 0 \quad \forall i=1,2, \ldots, n-1 .
\end{gathered}
$$

Therefore, if $\left(h_{i}-h_{i-1}\right) / c_{i}>\left(h_{i+1}-h_{i}\right) / c_{i+1}$, then $x_{i}^{*}(t)=x_{i+1}^{*}(t)$ for all $i=$ $1,2, \ldots, n-1$.

Define sequence $Q=\left\{Q_{i}\right\}_{i=1}^{n}$, where $Q_{i}=\left(h_{i}-h_{i-1}\right) / c_{i}$. Then, $Q$ must be one of the following three cases.

CASE I. The sequence $Q$ is an increasing sequence.

In this case, the optimal solution is shown in the next section.

CASE II. The sequence $Q$ is a strictly decreasing sequence. 
Then by (3.9), we know that $x_{n-1}^{*}(t)=x_{n}^{*}(t)$. So, in this case, we let $x_{n}(t)=$ $x_{n-1}(t)$ in (3.3), then the coefficients of $x_{n-1}(t)$ and $x_{n-1}^{\prime}(t)$ are $h_{n}-h_{n-1}$ and $c_{n}+c_{n-1}$, respectively.

Hence, sequence $Q$ becomes

$$
\left\{\frac{h_{1}-h_{0}}{c_{1}}, \ldots, \frac{h_{n-2}-h_{n-3}}{c_{n-2}}, \frac{h_{n}-h_{n-2}}{c_{n}+c_{n-1}}\right\}
$$

It is easy to see that if

$$
\frac{h_{n}-h_{n-1}}{c_{n}}<\frac{h_{n-1}-h_{n-2}}{c_{n-1}}
$$

then

$$
\frac{h_{n}-h_{n-1}}{c_{n}}<\frac{h_{n}-h_{n-2}}{c_{n}+c_{n-1}}<\frac{h_{n-1}-h_{n-2}}{c_{n-1}} .
$$

Thus, $\left(h_{n-2}-h_{n-3}\right) / c_{n-2}>\left(h_{n}-h_{n-2}\right) /\left(c_{n}+c_{n-1}\right)$, by (3.9), we then have $x_{n-2}^{*}(t)=x_{n-1}^{*}(t)$.

Continuing the process, we finally find that $x_{1}^{*}(t)=x_{2}^{*}(t)=\cdots=x_{n}^{*}(t)=$ $x^{*}(t)$, and the coefficients of $x^{*}(t)$ and $x^{*^{\prime}}(t)$ are $h_{n}-h_{0}$ and $\sum_{i=1}^{n} c_{i}$, respectively. Then, problem (3.3) reduces to

$$
\begin{aligned}
\operatorname{Max} \int_{0}^{x_{n}(T)} & {\left[v s-b\left(x_{n}(T)-s\right)\right] f(s) d s } \\
+ & \int_{x_{n}(T)}^{\infty}\left[v x_{n}(T)-p\left(s-x_{n}(T)\right)\right] f(s) d s \\
& -\int_{t_{n}}^{T}\left[\left[\sum_{i=1}^{n} c_{i}\right] x_{n}^{\prime 2}(t)+\left(h_{n}-h_{0}\right) x_{n}(t)\right] d t
\end{aligned}
$$

subject to $x_{n}\left(t_{n}\right)=0, h_{0}=0, t_{n} \geq 0, x_{n}^{\prime}(t) \geq 0$, for all $t \in\left[t_{n}, T\right]$, where $x_{n}(T)$, $t_{n}$ are free.

In this case, problem (3.3) reduces to the single-stage problem which is discussed in [2].

CASE III. The sequence $Q$ is neither increasing nor strictly decreasing.

Define $Q(i)=\left(h_{i}-h_{i-1}\right) / c_{i}=\bar{h}_{i} / \bar{c}_{i}$, then by (3.9), we use Algorithm 3.1 to check whether $x_{i}(t)=x_{i+1}(t)$, for all $i=1, \ldots, n-1$. 
Step 0. Form the sequence $Q(i)$. (When $Q(i)>Q(i+1)$, then $x_{i}(t)=x_{i+1}(t)$. In this situation, we recompute $Q(i)$ and let $Q(i+1)=$ ** in step 4.)

Step 1. $i=1, j=2$.

Step 2. If $Q(i)=$ “*” then $i=i+1$; if $i=n$, then go to step 7; else redo step 2; else if $Q(j)=$ “*," then $j=j+1$; if $j=n+1$, then go to step 7; else redo step 2; go to step 3 .

Step 3. If $Q(i)>Q(j)$, then go to step 4 else go to step 6 .

Step 4. $\bar{h}_{i}=\bar{h}_{i}+\bar{h}_{j}, \bar{c}_{i}=\bar{c}_{i}+\bar{c}_{j}$, and $Q(j)=$ “*”; print $x_{i}=x_{j}$; if $i=1$, then $j=j+1$; if $j=n+1$, then go to step 7 ;

else $j=i$ and go to step 5 . else go to step 2;

Step 5. $i=i-1$; if $Q(i)=$ "*," then redo step 5 else go to step 2 .

Step 6. $i=j ; j=j+1$; if $i=n$ or $j=n+1$, then go to step 7

Step 7. Stop. else go to step 2.

\section{ALGORITHM 3.1}

4. Optimal solution. To derive the optimal solution of Case I, note that (3.3) is not the standard form of calculus of variation, we first neglect the constraints $x_{i}^{\prime}(t) \geq 0$ for all $i$, and $x_{i}(t) \geq x_{j}(t)$ for $1 \leq i<j \leq n$, and consider the following problem:

$$
\begin{aligned}
\operatorname{Max} & \int_{0}^{x_{n}(T)}\left[v s-b\left(x_{n}(T)-s\right)\right] f(s) d s+\int_{x_{n}(T)}^{\infty}\left[v x_{n}(T)-p\left(s-x_{n}(T)\right)\right] f(s) d s \\
& -\sum_{i=1}^{n} \int_{t_{i}}^{T}\left[c_{i} x_{i}^{\prime 2}(t)+\left(h_{i}-h_{i-1}\right) x_{i}(t)\right] d t
\end{aligned}
$$

subject to $x_{i}\left(t_{i}\right)=0$ for all $i, x_{i}(T)=x_{n}(T)$ for all $i=1, \ldots, n-1, h_{i}>h_{i-1}$ for all $i=1,2, \ldots, n, h_{0}=0, t_{n} \geq t_{n-1} \geq \cdots \geq t_{1} \geq 0$, where $x_{i}(T), t_{i}$ are free for all $i$.

Let $\left(\bar{x}_{1}(t), \bar{x}_{2}(t), \ldots, \bar{x}_{n}(t)\right)$ be the optimal solution of (4.1).

CASE 1. Suppose that $\left(h_{i}-h_{i-1}\right) / c_{i} \leq\left(h_{i+1}-h_{i}\right) / c_{i+1}$ for all $i=1,2, \ldots, n-1$.

CASE 1.1. If $\bar{t}_{i}=0$ for all $i$, then the optimal solution $\bar{x}_{i}(t)$, for all $i$, must satisfy the following necessary conditions [5, pages 67-68]:

$$
\begin{gathered}
h_{i}-h_{i-1}=2 c_{i} \bar{x}_{i}^{\prime \prime}(t) \\
-\sum_{i=1}^{n} 2 c_{i} \bar{x}_{i}^{\prime}(T)+p+v-(p+v+b) F\left(\bar{x}_{n}(T)\right)=0 .
\end{gathered}
$$


Using the boundary conditions and $\bar{x}_{i}(T)=\bar{x}_{n}(T),(4.2)$ yields

$$
\bar{x}_{i}(t)=\frac{h_{i}-h_{i-1}}{4 c_{i}} t^{2}+\left[\frac{\bar{x}_{n}(T)}{T}-\frac{h_{i}-h_{i-1}}{4 c_{i}} T\right] t \quad \forall i=1,2, \ldots, n .
$$

From (4.3), we have

$$
-h_{n} T-\sum_{i=1}^{n} 2 c_{i}\left[\frac{\bar{x}_{n}(T)}{T}-\frac{h_{i}-h_{i-1}}{4 c_{i}} T\right]+p+v-(p+v+b) F\left(\bar{x}_{n}(T)\right)=0 .
$$

Thus, $\bar{x}_{n}(T)$ is determined by (4.5).

It is easy to see that $\bar{x}_{i}(t)-\bar{x}_{j}(t) \geq 0$ for $1 \leq i<j \leq n$. For each $i$, since $\bar{x}_{i}^{\prime \prime}(t)>0, \bar{x}_{i}^{\prime}(t) \geq 0$ if and only if $\bar{x}_{i}^{\prime}(0) \geq 0$. It is easy to see that $\bar{x}_{i}^{\prime}(0) \geq 0$, for all $i$ if and only if $\bar{x}_{n}^{\prime}(0) \geq 0$, and by (4.4) if and only if

$$
\bar{x}_{n}(T) \geq \frac{h_{n}-h_{n-1}}{4 c_{n}} T^{2} .
$$

Let $G$ be the function of $\bar{x}_{n}(T)$ :

$$
G\left(\bar{x}_{n}(T)\right)=-h_{n} T-\sum_{i=1}^{n} 2 c_{i}\left[\frac{\bar{x}_{n}(T)}{T}-\frac{h_{i}-h_{i-1}}{4 c_{i}} T\right]+p+v-(p+v+b) F\left(\bar{x}_{n}(T)\right) .
$$

It is easy to see that $G^{\prime}\left(\bar{x}_{n}(T)\right)<0$, so (4.6) holds if and only if $G\left(\left(\left(h_{n}-\right.\right.\right.$ $\left.\left.\left.h_{n-1}\right) / 4 c_{n}\right) T^{2}\right) \geq 0$, that is,

$$
p+v \geq h_{n} T+\sum_{i=1}^{n} 2 c_{i}\left[\frac{h_{n}-h_{n-1}}{4 c_{n}} T-\frac{h_{i}-h_{i-1}}{4 c_{i}} T\right]+(p+v+b) F\left(\frac{h_{n}-h_{n-1}}{4 c_{n}} T^{2}\right) .
$$

RESULT 1. If inequality (4.8) holds, then $\bar{x}_{i}(t)$ in (4.4) is also the optimal solution of (3.3).

CASE 1.2. If $0<\bar{t}_{1} \leq \bar{t}_{2} \leq \cdots \leq \bar{t}_{n}$, then the optimal solution $\bar{x}_{i}(t)$, for all $i$, must satisfy the following necessary conditions (see [5, pages 67-68]):

$$
\begin{gathered}
h_{i}-h_{i-1}=2 c_{i} \bar{x}_{i}^{\prime \prime}(t), \\
-\bar{x}_{i}^{\prime 2}\left(\bar{t}_{i}\right)-\left(h_{i}-h_{i-1}\right) \bar{x}_{i}\left(\bar{t}_{i}\right)-\bar{x}_{i}^{\prime}\left(\bar{t}_{i}\right)\left(-2 \bar{x}_{i}^{\prime}\left(\bar{t}_{i}\right)\right)=0, \quad i=1,2, \ldots, n, \\
-\sum_{i=1}^{n} 2 c_{i} \bar{x}_{i}^{\prime}(T)+p+v-(p+v+b) F\left(\bar{x}_{n}(T)\right)=0 .
\end{gathered}
$$

From (4.10), we know that $\bar{x}_{i}^{\prime}\left(\bar{t}_{i}\right)=0$. Hence, (4.9) yields

$$
\bar{x}_{i}(t)=\frac{h_{i}-h_{i-1}}{4 c_{i}}\left(t-\bar{t}_{i}\right)^{2}, \quad t \in\left[\bar{t}_{i}, T\right]
$$


Note that $\bar{x}_{i}(T)=\bar{x}_{n}(T)$, so

$$
\bar{t}_{i}=T-\sqrt{\frac{h_{1}-h_{0}}{c_{1}} \frac{c_{i}}{h_{i}-h_{i-1}}}\left(T-\bar{t}_{1}\right) \quad \forall i=2,3, \ldots, n .
$$

From (4.11), we have

$$
\begin{aligned}
& -\sum_{i=1}^{n}\left(h_{i}-h_{i-1}\right)\left[\sqrt{\frac{h_{1}-h_{0}}{c_{1}} \frac{c_{i}}{h_{i}-h_{i-1}}}\left(T-\bar{t}_{1}\right)\right] \\
& +p+v-(p+v+b) F\left(\frac{h_{1}-h_{0}}{4 c_{1}}\left(T-\bar{t}_{1}\right)^{2}\right)=0 .
\end{aligned}
$$

Thus, $\bar{t}_{1}$ is determined by (4.14) and $\bar{t}_{i}$ is determined by (4.13) for all $i=$ $2,3, \ldots, n$.

Let $G$ be the function of $\bar{t}_{1}$ :

$$
\begin{aligned}
G\left(\bar{t}_{1}\right)= & -\sum_{i=1}^{n}\left(h_{i}-h_{i-1}\right)\left[\sqrt{\frac{h_{1}-h_{0}}{c_{1}} \frac{c_{i}}{h_{i}-h_{i-1}}}\left(T-\bar{t}_{1}\right)\right] \\
& +p+v-(p+v+b) F\left(\frac{h_{1}-h_{0}}{4 c_{1}}\left(T-\bar{t}_{1}\right)^{2}\right) .
\end{aligned}
$$

Clearly, $G^{\prime}\left(\bar{t}_{1}\right)>0$, so $\bar{t}_{1}$ exists if and only if $G(0)<0$, that is,

$$
p+v<\sum_{i=1}^{n}\left(h_{i}-h_{i-1}\right)\left[\sqrt{\frac{h_{1}-h_{0}}{c_{1}} \frac{c_{i}}{h_{i}-h_{i-1}}} T\right]+(p+v+b) F\left(\frac{h_{1}-h_{0}}{4 c_{1}} T^{2}\right) .
$$

RESULT 2. If inequality (4.16) holds, then $\bar{x}_{i}(t)$ in (4.12) is also the optimal solution of (3.3).

CASE 1.3. If $\bar{t}_{1}=\bar{t}_{2}=\cdots=\bar{t}_{k}=0,0<\bar{t}_{k+1} \leq \bar{t}_{k+2} \leq \cdots \leq \bar{t}_{n}$, and $k=$ $1,2, \ldots, n-1$, then the optimal solution $\bar{x}_{i}$, for all $i$, must satisfy the following necessary conditions (see [5, pages 105-106]):

$$
\begin{gathered}
h_{i}-h_{i-1}=2 c_{i} \bar{x}_{i}^{\prime \prime}(t), \quad \forall i=1,2, \ldots, n, \\
-\bar{x}_{i}^{\prime 2}\left(\bar{t}_{i}\right)-\left(h_{i}-h_{i-1}\right) \bar{x}_{i}\left(\bar{t}_{i}\right)-\bar{x}_{i}^{\prime}\left(\bar{t}_{i}\right)\left(-2 \bar{x}_{i}^{\prime}\left(\bar{t}_{i}\right)\right)=0, \quad \forall i=k+1, \ldots, n, \\
-\sum_{i=1}^{n} 2 c_{i} \bar{x}_{i}^{\prime}(T)+p+v+(p+v+b) F\left(\bar{x}_{n}(T)\right)=0 .
\end{gathered}
$$

From (4.18), we find that $\bar{x}_{i}^{\prime}\left(\bar{t}_{i}\right)=0$, for all $i=k+1, \ldots, n$, then (4.17) yields

$$
\bar{x}_{i}(t)=\frac{h_{i}-h_{i-1}}{4 c_{i}}\left(t-\bar{t}_{i}\right)^{2} \quad \forall i=k+1, k+2, \ldots, n .
$$


On the other hand, (4.17) yields

$$
\bar{x}_{i}(t)=\frac{h_{i}-h_{i-1}}{4 c_{i}} t^{2}+\left[\frac{\bar{x}_{n}(T)}{T}-\frac{h_{i}-h_{i-1}}{4 c_{i}} T\right] t \quad \forall i=1,2, \ldots, k
$$

From (4.20) and using the boundary conditions $\bar{x}_{k+1}(T)=\bar{x}_{i}(T)$, for all $i=$ $k+2, \ldots, n$, we have

$$
\frac{h_{k+1}-h_{k}}{4 c_{k+1}}\left(T-\bar{t}_{k+1}\right)^{2}=\frac{h_{i}-h_{i-1}}{4 c_{i}}\left(T-\bar{t}_{i}\right)^{2} \quad \forall i=k+2, \ldots, n .
$$

Hence,

$$
\bar{t}_{i}=T-\sqrt{\frac{h_{k+1}-h_{k}}{c_{k+1}} \frac{c_{i}}{h_{i}-h_{i-1}}}\left(T-\bar{t}_{k+1}\right) \quad \forall i=k+2, \ldots, n .
$$

Thus, from (4.19), we have

$$
\begin{aligned}
-h_{k} T & -\sum_{i=1}^{k} 2 c_{i}\left[\frac{1}{T} \frac{h_{k+1}-h_{k}}{4 c_{k+1}}\left(T-\bar{t}_{k+1}\right)^{2}-\frac{h_{i}-h_{i-1}}{4 c_{i}} T\right] \\
& -\sum_{i=k+1}^{n}\left(h_{i}-h_{i-1}\right) \sqrt{\frac{h_{k+1}-h_{k}}{c_{k+1}} \frac{c_{i}}{h_{i}-h_{i-1}}}\left(T-\bar{t}_{k+1}\right) \\
& +p+v-(p+v+b) F\left(\frac{h_{k+1}-h_{k}}{4 c_{k+1}}\left(T-\bar{t}_{k+1}\right)^{2}\right)=0 .
\end{aligned}
$$

Hence, the value of $\bar{t}_{k+1}$ is determined by (4.24) and the value of $\bar{t}_{i}$ is then given by (4.23).

For $1 \leq i<j \leq k$, it is easy to see that $\bar{x}_{i}(t)-\bar{x}_{j}(t) \geq 0$. Next, we show that $\bar{x}_{k}(t)-\bar{x}_{k+1}(t) \geq 0$. From (4.20) and (4.21), we have

$$
\begin{aligned}
\bar{x}_{k}(t)-\bar{x}_{k+1}(t)= & \frac{h_{k}-h_{k-1}}{4 c_{k}} t^{2}+\left[\frac{1}{T} \frac{h_{k+1}-h_{k}}{4 c_{k+1}}\left(T-\bar{t}_{k+1}\right)^{2}-\frac{h_{k}-h_{k-1}}{4 c_{k}} T\right] t \\
& -\frac{h_{k+1}-h_{k}}{4 c_{k+1}}\left(t-\bar{t}_{k+1}\right)^{2} .
\end{aligned}
$$

The right-hand side of the above equation is a polynomial of degree 2 and $\bar{x}_{k}(T)-\bar{x}_{k+1}(T)=0$. So, there exists $\gamma \in \mathbb{R}$ such that

$$
\bar{x}_{k}(t)-\bar{x}_{k+1}(t)=\left(\frac{h_{k}-h_{k-1}}{4 c_{k}}-\frac{h_{k+1}-h_{k}}{4 c_{k+1}}\right)(t-\gamma)(t-T) .
$$

Since $\bar{x}_{k}\left(\bar{t}_{k+1}\right)-\bar{x}_{k+1}\left(\bar{t}_{k+1}\right)>0$, this implies that $\gamma<\bar{t}_{k+1}<T$. Hence, $\bar{x}_{k}(t)-$ $\bar{x}_{k+1}(t) \geq 0$ for all $t \in\left[\bar{t}_{k+1}, T\right]$. For $k+1 \leq i<j \leq n$, it can be shown that $\bar{x}_{i}(t)-\bar{x}_{j}(t) \geq 0$ by the same way. Hence, $\bar{x}_{i}(t)-\bar{x}_{j}(t) \geq 0$ for $1 \leq i<j \leq n$.

For $i=k+1, \ldots, n$, we have $\bar{x}_{i}^{\prime}(t) \geq 0$. For $i=1,2, \ldots, k$ since $\bar{x}_{i}^{\prime \prime}(t)=\left(h_{i}-\right.$ $\left.h_{i-1}\right) / 2 c_{i}>0$, we have $\bar{x}_{i}^{\prime}(t) \geq 0$, for all $t \in\left[\bar{t}_{i}, T\right]$, if and only if $\bar{x}_{i}^{\prime}(0) \geq 0$. 
Since $\bar{x}_{i}^{\prime}(t)=\left(\left(h_{i}-h_{i-1}\right) / 2 c_{i}\right) t+\left[\bar{x}_{n}(T) / T-\left(\left(h_{i}-h_{i-1}\right) / 4 c_{i}\right) T\right]$,

$$
\bar{x}_{i}^{\prime}(0)=\frac{\bar{x}_{n}(T)}{T}-\frac{h_{i}-h_{i-1}}{4 c_{i}} T \quad \forall i=1,2, \ldots, k .
$$

The fact that $Q$ is an increasing sequence implies that $\bar{x}_{i}^{\prime}(0) \geq \bar{x}_{k}^{\prime}(0)$ for all $i=1,2, \ldots, k$. Therefore, $\bar{x}_{i}^{\prime}(0) \geq 0$, for all $i=1,2, \ldots, k$, if and only if $\bar{x}_{k}^{\prime}(0) \geq 0$ and by the expression of $\bar{x}_{k}^{\prime}(0)$ if and only if

$$
\bar{x}_{n}(T) \geq \frac{h_{k}-h_{k-1}}{4 c_{k}} T^{2} .
$$

This implies that

$$
\begin{gathered}
\frac{h_{k+1}-h_{k}}{4 c_{k+1}}\left(T-\bar{t}_{k+1}\right)^{2} \geq \frac{h_{k}-h_{k-1}}{4 c_{k}} T^{2}, \\
0<\bar{t}_{k+1} \leq T-\sqrt{\frac{h_{k}-h_{k-1}}{c_{k}} \frac{c_{k+1}}{h_{k+1}-h_{k}}} T .
\end{gathered}
$$

Let $G$ be the function of $\bar{t}_{k+1}$ :

$$
\begin{aligned}
G\left(\bar{t}_{k+1}\right)= & -h_{k} T-\sum_{i=1}^{k} 2 c_{i}\left[\frac{1}{T} \frac{h_{k+1}-h_{k}}{4 c_{k+1}}\left(T-\bar{t}_{k+1}\right)^{2}-\frac{h_{i}-h_{i-1}}{4 c_{i}} T\right] \\
& -\sum_{i=k+1}^{n}\left(h_{i}-h_{i-1}\right) \sqrt{\frac{h_{k+1}-h_{k}}{c_{k+1}} \frac{c_{i}}{h_{i}-h_{i-1}}}\left(T-\bar{t}_{k+1}\right) \\
& +p+v-(p+v+b) F\left(\frac{h_{k+1}-h_{k}}{4 c_{k+1}}\left(T-\bar{t}_{k+1}\right)^{2}\right) .
\end{aligned}
$$

It is easy to see that $G^{\prime}\left(\bar{t}_{k+1}\right)>0$. Thus, by (4.29), we know that $\bar{t}_{k+1}$ exists if and only if $G(0)<0$ and $G\left(T-\sqrt{\left(\left(h_{k}-h_{k-1}\right) / c_{k}\right)\left(c_{k+1} /\left(h_{k+1}-h_{k}\right)\right)} T\right) \geq 0$, that is,

$$
\begin{aligned}
h_{k} T+ & \sum_{i=1}^{k} 2 c_{i}\left[\frac{h_{k}-h_{k-1}}{4 c_{k}} T-\frac{h_{i}-h_{i-1}}{4 c_{i}} T\right] \\
& +\sum_{i=k+1}^{n}\left(h_{i}-h_{i-1}\right) \sqrt{\frac{h_{k}-h_{k-1}}{c_{k}} \frac{c_{i}}{h_{i}-h_{i-1}}} T \\
& +(p+v+b) F\left(\frac{h_{k}-h_{k-1}}{4 c_{k}} T^{2}\right) \\
\leq & p+v<h_{k} T+\sum_{i=1}^{k} 2 c_{i}\left[\frac{h_{k+1}-h_{k}}{4 c_{k+1}} T-\frac{h_{i}-h_{i-1}}{4 c_{i}} T\right] \\
& +\sum_{i=k+1}^{n}\left(h_{i}-h_{i-1}\right) \sqrt{\frac{h_{k+1}-h_{k}}{c_{k+1}} \frac{c_{i}}{h_{i}-h_{i-1}}} T \\
& +(p+v+b) F\left(\frac{h_{k+1}-h_{k}}{4 c_{k+1}} T^{2}\right) .
\end{aligned}
$$


RESULT 3. If inequality (4.31) holds, then $\bar{x}_{i}(t)$ in (4.20) and (4.21) is also the optimal solution of (3.3).

Hence, by Results 1,2 , and 3, the optimal solution $\left(x_{1}^{*}(t), x_{2}^{*}(t), \ldots, x_{n}^{*}(t)\right)$ of (3.3) is as follows.

CASE 1. Suppose that $\left(h_{i}-h_{i-1}\right) / c_{i} \leq\left(h_{i+1}-h_{i}\right) / c_{i+1}$ for all $i=1,2, \ldots, n-1$.

CASE 1.1. If

$$
\begin{aligned}
p+v \geq & h_{n} T+\sum_{i=1}^{n} 2 c_{i}\left[\frac{h_{n}-h_{n-1}}{4 c_{n}} T-\frac{h_{i}-h_{i-1}}{4 c_{i}} T\right] \\
& +(p+v+b) F\left(\frac{h_{n}-h_{n-1}}{4 c_{n}} T^{2}\right),
\end{aligned}
$$

then

$$
x_{i}^{*}(t)=\frac{h_{i}-h_{i-1}}{4 c_{i}} t^{2}+\left[\frac{x_{n}^{*}(T)}{T}-\frac{h_{i}-h_{i-1}}{4 c_{i}} T\right] t, \quad \forall i=1,2, \ldots, n,
$$

where the value of $x_{n}^{*}(T)$ is determined by the following equation:

$$
-h_{n} T-\sum_{i=1}^{n} 2 c_{i}\left[\frac{x_{n}^{*}(T)}{T}-\frac{h_{i}-h_{i-1}}{4 c_{i}} T\right]+p+v-(p+v+b) F\left(x_{n}^{*}(T)\right)=0 .
$$

CASE 1.2. If

$$
\begin{aligned}
p+v< & \sum_{i=1}^{n}\left(h_{i}-h_{i-1}\right)\left[\sqrt{\frac{\left(h_{1}-h_{0}\right)}{c_{1}} \frac{c_{i}}{\left(h_{i}-h_{i-1}\right)}} T\right] \\
& +(p+v+b) F\left(\frac{\left(h_{1}-h_{0}\right)}{4 c_{1}} T^{2}\right)
\end{aligned}
$$

then

$$
x_{i}^{*}(t)=\frac{h_{i}-h_{i-1}}{4 c_{i}}\left(t-t_{i}^{*}\right)^{2}, \quad t \in\left[t_{i}^{*}, T\right], i=1,2, \ldots, n,
$$

where the value of $t_{1}^{*}$ is determined by the following equation:

$$
\begin{aligned}
& -\sum_{i=1}^{n}\left(h_{i}-h_{i-1}\right)\left[\sqrt{\frac{h_{1}-h_{0}}{c_{1}} \frac{c_{i}}{h_{i}-h_{i-1}}}\left(T-t_{1}^{*}\right)\right] \\
& \quad+p+v-(p+v+b) F\left(\frac{h_{1}-h_{0}}{4 c_{1}}\left(T-t_{1}^{*}\right)^{2}\right)=0,
\end{aligned}
$$

and the value of $t_{i}^{*}$ is given by

$$
t_{i}^{*}=T-\sqrt{\frac{h_{1}-h_{0}}{c_{1}} \frac{c_{i}}{h_{i}-h_{i-1}}}\left(T-t_{1}^{*}\right) \quad \forall i=2,3, \ldots, n .
$$


CASE 1.3. If

$$
\begin{aligned}
h_{k} T & +\sum_{i=1}^{k} 2 c_{i}\left[\frac{h_{k}-h_{k-1}}{4 c_{k}} T-\frac{h_{i}-h_{i-1}}{4 c_{i}} T\right] \\
& +\sum_{i=k+1}^{n}\left(h_{i}-h_{i-1}\right) \sqrt{\frac{h_{k}-h_{k-1}}{c_{k}} \frac{c_{i}}{h_{i}-h_{i-1}}} T \\
& +(p+v+b) F\left(\frac{h_{k}-h_{k-1}}{4 c_{k}} T^{2}\right) \\
\leq & +v<h_{k} T+\sum_{i=1}^{k} 2 c_{i}\left[\frac{h_{k+1}-h_{k}}{4 c_{k+1}} T-\frac{h_{i}-h_{i-1}}{4 c_{i}} T\right] \\
& +\sum_{i=k+1}^{n}\left(h_{i}-h_{i-1}\right) \sqrt{\frac{h_{k+1}-h_{k}}{c_{k+1}} \frac{c_{i}}{h_{i}-h_{i-1}}} T \\
& +(p+v+b) F\left(\frac{h_{k+1}-h_{k}}{4 c_{k+1}} T^{2}\right),
\end{aligned}
$$

then

$$
\begin{aligned}
& x_{i}^{*}(t)=\frac{h_{i}-h_{i-1}}{4 c_{i}}\left(t-t_{i}^{*}\right)^{2}, \quad \forall i=k+1, k+2, \ldots, n, \\
& x_{i}^{*}(t)=\frac{h_{i}-h_{i-1}}{4 c_{i}} t^{2}+\left[\frac{x_{n}^{*}(T)}{T}-\frac{h_{i}-h_{i-1}}{4 c_{i}} T\right] t, \quad \forall i=1,2, \ldots, k,
\end{aligned}
$$

where the value of $t_{k+1}^{*}$ is determined by the following equation:

$$
\begin{array}{r}
-h_{k} T-\sum_{i=1}^{k} 2 c_{i}\left[\frac{1}{T} \frac{h_{k+1}-h_{k}}{4 c_{k+1}}\left(T-\bar{t}_{k+1}\right)^{2}-\frac{h_{i}-h_{i-1}}{4 c_{i}} T\right] \\
-\sum_{i=k+1}^{n}\left(h_{i}-h_{i-1}\right) \sqrt{\frac{h_{k+1}-h_{k}}{c_{k+1}} \frac{c_{i}}{h_{i}-h_{i-1}}}\left(T-t_{k+1}^{*}\right) \\
+p+v-(p+v+b) F\left(\frac{h_{k+1}-h_{k}}{4 c_{k+1}}\left(T-t_{k+1}^{*}\right)^{2}\right)=0,
\end{array}
$$

then the value of $t_{i}^{*}$ is given by

$$
t_{i}^{*}=T-\sqrt{\frac{h_{k+1}-h_{k}}{c_{k+1}} \frac{c_{i}}{h_{i}-h_{i-1}}}\left(T-t_{k+1}^{*}\right) \quad \forall i=k+2, \ldots, n .
$$

CASE 2. Suppose that $\left(h_{i}-h_{i-1}\right) / c_{i}>\left(h_{i+1}-h_{i}\right) / c_{i+1}$ for all $i=1,2, \ldots, n-1$.

CASE 2.1. If $p+v \geq\left(h_{n}-h_{0}\right) T+(p+v+b) F\left(\left(\left(h_{n}-h_{0}\right) / 4 \sum c_{i}\right) T^{2}\right)$, then

$$
x^{*}(t)=\frac{h_{n}-h_{0}}{4 \sum c_{i}} t^{2}+\left[\frac{x_{n}^{*}(T)}{T}-\frac{h_{n}-h_{0}}{4 \sum c_{i}} T\right] t, \quad 0 \leq t \leq T,
$$


where the value of $x_{n}^{*}(T)$ is determined by the following equation:

$$
\left(h_{n}-h_{0}\right) T+2 \sum_{i=1}^{n} c_{i}\left[\frac{x_{n}^{*}(T)}{T}-\frac{h_{n}-h_{0}}{4 \sum c_{i}} T\right]=p+v-(p+v+b) F\left(x_{n}^{*}(T)\right) .
$$

CASE 2.2. If $p+v<\left(h_{n}-h_{0}\right) T+(p+v+b) F\left(\left(\left(h_{n}-h_{0}\right) / 4 \sum c_{i}\right) T^{2}\right)$, then

$$
x_{i}^{*}(t)=\frac{h_{n}-h_{0}}{4 \sum c_{i}}\left(t-t_{n}^{*}\right)^{2} \quad \forall i, \forall t \in\left[t_{n}^{*}, T\right],
$$

where the value of $t_{n}^{*}$ is determined by the following equation:

$$
p+v=\left(h_{n}-h_{0}\right)\left(T-t_{n}^{*}\right)+(p+v+b) F\left(\frac{h_{n}-h_{0}}{4 \sum c_{i}}\left(T-t_{n}^{*}\right)^{2}\right) .
$$

5. Conclusion. To analyze the characteristics of the optimal solution, the $Q$ sequence should be considered first:

$$
Q=\left\{Q_{i}\right\}_{i=1}^{n}, \quad Q_{i}=\frac{h_{i}-h_{i-1}}{c_{i}} .
$$

Then there are some features of the optimal solution that are described as follows:

(1) if $Q$ is an increasing sequence, then the optimal solution is of Case 1. In this situation, for Case 1.1, the optimal inventory size $x_{n}^{*}(T)$ will be greater than $\left(\left(h_{n}-h_{n-1}\right) / 4 c_{n}\right) T^{2}$. For Case 1.2 , the optimal inventory size $x_{n}^{*}(T)$ will be less than $\left(\left(h_{1}-h_{0}\right) / 4 c_{1}\right) T^{2}$. Otherwise, the optimal inventory size will be between them;

(2) if $Q$ is a strictly decreasing sequence, then the optimal solution is of Case 2. Furthermore, if $\left(h_{i}-h_{i-1}\right) / c_{i}=\left(h_{i+1}-h_{i}\right) / c_{i+1}$ is established, then the optimal solutions of Case 1 will reduce to that of Case 2 , that is, the multistage problem will reduce to the single-stage problem like [2]. Precisely speaking, the optimal production functions of all stages are the same;

(3) there are two types of the optimal production plan for Cases I, II, and III: immediate production and postponed production.

Briefly speaking, $\left(h_{i}-h_{i-1}\right) / c_{i}$, the ratio of the incremental holding cost to production cost per unit of $i$ th semifinished goods, is an important factor which determines whether the optimal production functions are the same or not.

\section{REFERENCES}

[1] P. J. Billington, J. O. McClain, and L. J. Thomas, Mathematical programming approaches to capacity-constrained MRP system: review, formulation and problem reduction, Management Sci. 29 (1983), no. 10, 1126-1141. 
[2] M. S. Chen and Y. C. Chen, A production inventory problem with random point demand, Yugosl. J. Oper. Res. 4 (1994), no. 1, 35-42.

[3] M. S. Chen and C. T. Lin, Effects of centralization on expected costs in a multilocation newsboy problem, J. Oper. Res. Soc. 40 (1989), no. 6, 597-602.

[4] G. E. Eppen, Effects of centralization on expected costs in multi-location newsboy problem, Management Sci. 25 (1979), no. 5, 498-501.

[5] M. I. Kamien and N. L. Schwartz, Dynamic Optimization, Dynamic Economics: Theory and Applications, vol. 4, North-Holland Publishing, New York, 1981.

[6] S. Love, A facilities in series inventory model with nested schedules, Management Sci. 18 (1972), no. 5, 327-338.

[7] W. Zangwill, A backlogging model and multi-echelon model of a dynamic economic lot-size production system - a network approach, Management Sci. 15 (1969), no. 9, 506-527.

Ying-Chieh Chen: Department of Applied Statistics and Information Science, Ming Chuan University, 250 Chung Shan North Road, Section 5, Shihlin District, Taipei 111, Taiwan

E-mail address: ychchen@mcu.edu.tw 


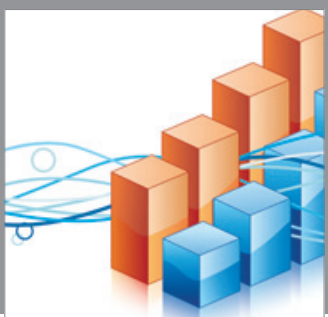

Advances in

Operations Research

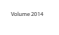

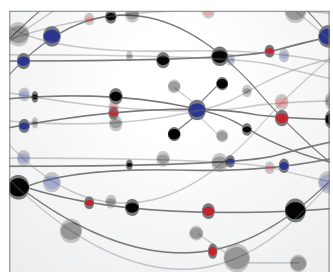

\section{The Scientific} World Journal
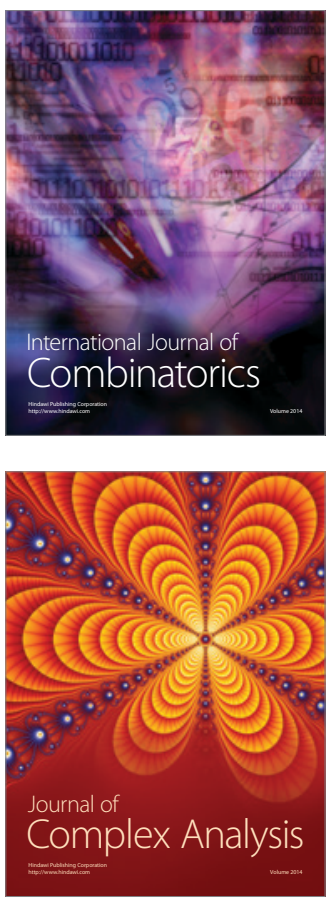

International Journal of

Mathematics and

Mathematical

Sciences
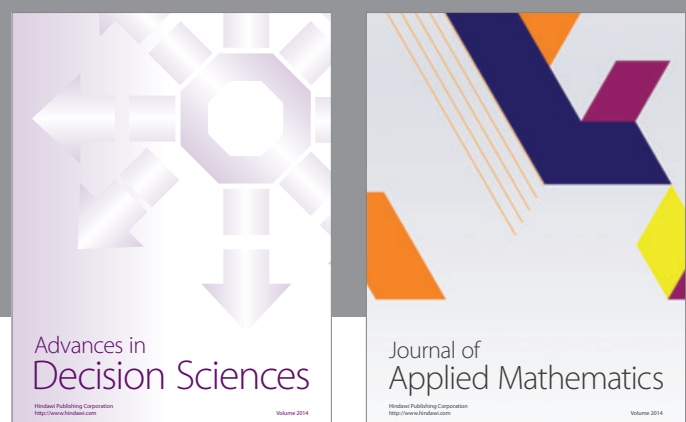

Journal of

Applied Mathematics
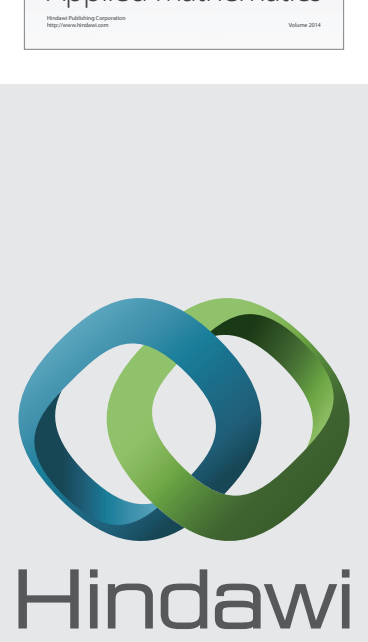

Submit your manuscripts at http://www.hindawi.com
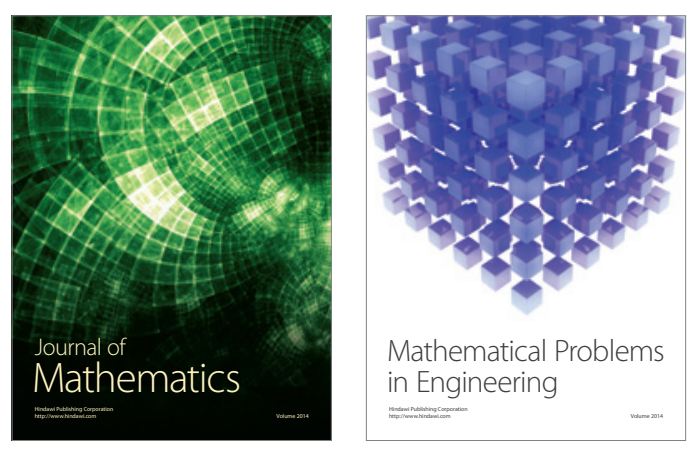

Mathematical Problems in Engineering
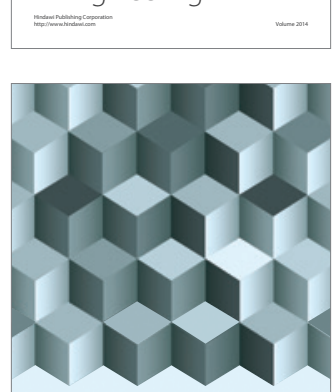

Journal of

Function Spaces
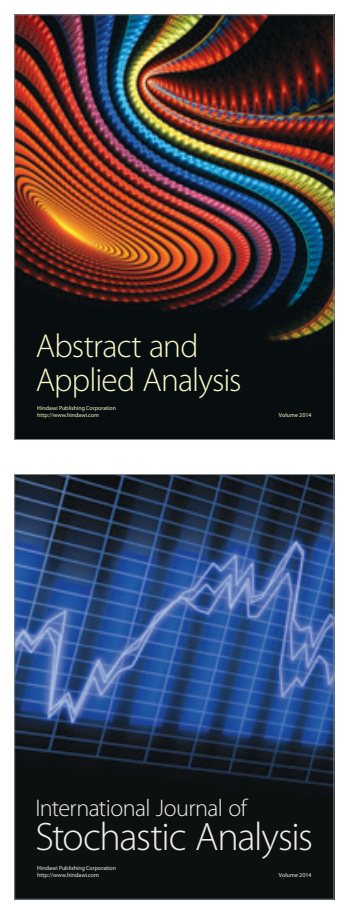

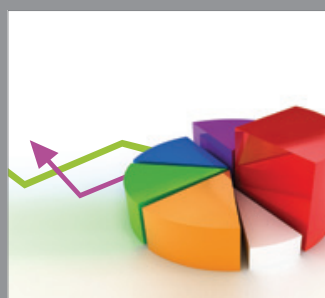

ournal of

Probability and Statistics

Promensencen
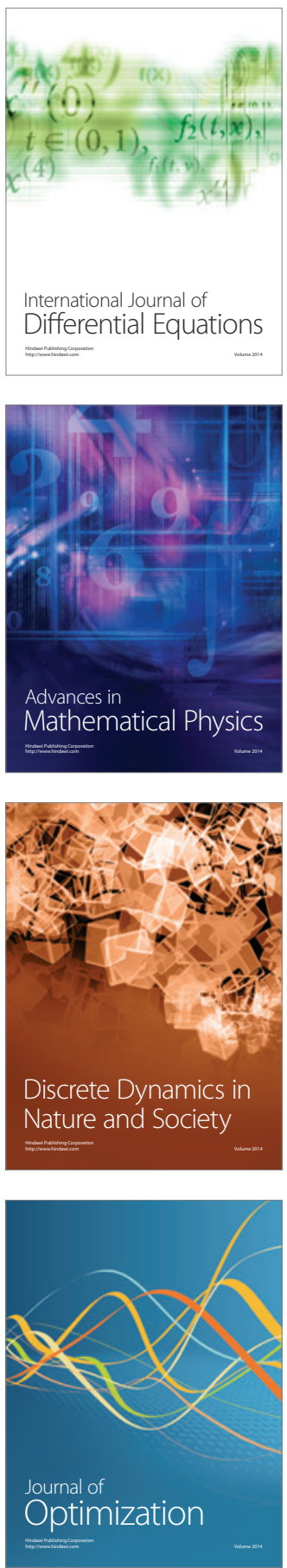